\title{
Animal source foods have a positive impact on the primary school test scores of Kenyan schoolchildren in a cluster-randomised, controlled feeding intervention trial
}

\author{
Judie L. Hulett ${ }^{1}$, Robert E. Weiss ${ }^{2}$, Nimrod O. Bwibo ${ }^{3}$, Osman M. Galal ${ }^{1}$, Natalie Drorbaugh ${ }^{1}$ and \\ Charlotte G. Neumann ${ }^{1,4 *}$ \\ ${ }^{1}$ Department of Community Health Sciences, Jonathan and Karin Fielding School of Public Health, University of California, \\ Los Angeles, Los Angeles, CA 90095, USA \\ ${ }^{2}$ Department of Biostatistics, Jonathan and Karin Fielding School of Public Health, University of California, Los Angeles, \\ Los Angeles, CA 90095, USA \\ ${ }^{3}$ Faculty of Medicine, University of Nairobi, Nairobi, Kenya \\ ${ }^{4}$ Department of Pediatrics, David Geffen School of Medicine, University of California, Los Angeles, Los Angeles, CA 90095 , USA \\ (Submitted 5 March 2013 - Final revision received 2 September 2013 - Accepted 3 September 2013 - First published online 30 October 2013)
}

\begin{abstract}
Micronutrient deficiencies and suboptimal energy intake are widespread in rural Kenya, with detrimental effects on child growth and development. Sporadic school feeding programmes rarely include animal source foods (ASF). In the present study, a cluster-randomised feeding trial was undertaken to determine the impact of snacks containing ASF on district-wide, end-term standardised school test scores and nutrient intake. A total of twelve primary schools were randomly assigned to one of three isoenergetic feeding groups (a local plantbased stew (githeri) with meat, githeri plus whole milk or githeri with added oil) or a control group receiving no intervention feeding. After the initial term that served as baseline, children were fed at school for five consecutive terms over two school years from 1999 to 2001. Longitudinal analysis was used controlling for average energy intake, school attendance, and baseline socio-economic status, age, sex and maternal literacy. Children in the Meat group showed significantly greater improvements in test scores than those in all the other groups, and the Milk group showed significantly greater improvements in test scores than the Plain Githeri (githeri + oil) and Control groups. Compared with the Control group, the Meat group showed significant improvements in test scores in Arithmetic, English, Kiembu, Kiswahili and Geography. The Milk group showed significant improvements compared with the Control group in test scores in English, Kiswahili, Geography and Science. Folate, Fe, available Fe, energy per body weight, vitamin $\mathrm{B}_{12}$, Zn and riboflavin intake were significant contributors to the change in test scores. The greater improvements in test scores of children receiving ASF indicate improved academic performance, which can result in greater academic achievement.
\end{abstract}

Key words: Animal source foods: Schoolchildren: School test scores: Kenya

Malnutrition affects over 300 million school-aged children throughout the developing world ${ }^{(1)}$. Children who are undernourished are susceptible to decelerated growth rates, with stunting, multiple micronutrient deficiencies, anaemia (particularly Fe-deficiency anaemia), diminished cognitive function, poor school performance, and increased morbidity and mortality ${ }^{(2-6)}$. Poor dietary quality due to limited intake of a variety of animal source foods (ASF), including milk, is a contributing factor for malnutrition and multiple micronutrient deficiencies among many of these children ${ }^{(7)}$. Micronutrient deficiencies, particularly $\mathrm{Fe}, \mathrm{Zn}$, iodine and vitamin $\mathrm{B}_{12}$ deficiencies, are of particular concern. Micronutrient deficiencies occur in part due to consumption of diets that lack ASF and consist mainly of staple foods such as cereals and legumes that are devoid of vitamin $\mathrm{B}_{12}$ and have high fibre and phytate content, resulting in impaired bioavailability of micronutrients such as $\mathrm{Fe}$ and $\mathrm{Zn}^{(8-13)}$. In addition, repeated intestinal infections and parasites with resultant diarrhoea contribute to malabsorption, blood loss, malnutrition, and impaired growth and development ${ }^{(14)}$.

Fe deficiency with or without anaemia is among the most prevalent and devastating deficiencies in developing countries

Abbreviations: ASF, animal source foods; CNP, Child Nutrition Project; NCRSP, Nutrition Collaborative Research and Support Program; RPM, Raven's Progressive Matrices; SES, socio-economic status.

*Corresponding author: C. G. Neumann, fax +1 310794 1805, email cneumann@ucla.edu 
and results in retarded cognitive and motor development, growth, immune function and physical activity ${ }^{(15-18)}$. The major causes of $\mathrm{Fe}$ deficiency include poor bioavailability of $\mathrm{Fe}$ in plant-based diets, inadequate meat consumption (which inherently contains readily absorbable haem $\mathrm{Fe}$ ), and blood loss due to parasitic infections, particularly hookworm infections ${ }^{(11,19,20)}$. Vitamin $\mathrm{B}_{12}$ deficiency occurs in populations consuming primarily plant-based diets and is associated with delayed development, lethargy, anaemia and poor school performance in children and adolescents ${ }^{(5,21-25)}$. Zn deficiency is associated with the impairment of multiple biological functions, including protein synthesis, growth and cell-mediated immunity, and is associated with delays in cognitive development, lower school scores and lower levels of physical activity ${ }^{(26-28)}$. Iodine deficiency of all degrees of severity also contributes to cognitive impairment ${ }^{(29)}$.

Poor health and nutritional deficiencies affect school performance and impair long-term cognitive development in primary school children, with undernourished children demonstrating lower school attendance, lower school performance scores and more health-related problems than their well-nourished peers ${ }^{(18,30-36)}$. The adverse effects of macro- and micronutrient deficiencies in infancy and childhood may not be fully reversible and may continue to affect cognitive function into the school age years and adulthood $^{(14,18,37,38)}$. However, some studies have demonstrated improvements in educational attainment and cognitive performance following adequate nutrition or catch-up growth $^{(39,40)}$. There have been few food-based randomised intervention studies to test the ability of ASF to improve school performance and cognitive function.

Results from the Nutrition Collaborative Research Support Program (NCRSP), an observational study carried out in Kenya, Egypt and Mexico during the mid-1980s, pointed to the need for a randomised controlled feeding intervention study to test for causal linkages between ASF and a number of functional outcomes ${ }^{(41)}$. The NCRSP study showed that diets deficient in ASF and $\mathrm{Fe}$, vitamin $\mathrm{B}_{12}$ and $\mathrm{Zn}$ were associated with poor school performance ${ }^{(41)}$. Strong positive statistical associations were observed between children's meat intake and cognitive function, development and growth ${ }^{(42)}$. These finding stimulated the Child Nutrition Project (CNP) study, the cluster-randomised feeding intervention trial reported herein, to test for causal relationships between intake of ASF and improvement in health, cognition, school performance and development in schoolchildren ${ }^{(43)}$. Cluster randomisation was selected, as it would have been logistically impossible to prepare and deliver different feedings within the same school or to prepare and deliver feedings to individual households.

The present study evaluated the effect of the CNP feeding intervention trial on school performance in 360 Kenyan schoolchildren using the changes in end-term test scores over five consecutive terms (19 months). It was hypothesised that children supplemented with ASF would show greater improvement in term-end school test scores than those who received plant-based supplements or the control group.

\section{Experimental methods}

In the present study, data collected in the CNP clusterrandomised, controlled school feeding intervention study conducted from 1998 to 2001 in rural Kenya were used. No primary school feeding programmes existed in the study area. In the CNP study, two cohorts were enrolled exactly 1 year apart as the schools were closed due to a prolonged teachers' strike during the cohort I study and also because of a prolonged drought. Children in each cohort were given feedings at school and studied for three school terms per year over 2 years for a total of 9 months/year: cohort I from 1998 to 2000 and cohort II from 1999 to 2001. Only data obtained for cohort II are reported herein, since complete end-term test score information was not readily available for cohort I.

\section{Study location}

The CNP study was carried out in central Kenya's rural Embu District, Eastern Province, about $193 \mathrm{~km}$ northeast of Nairobi. Subsistence farming on one- or two-acre farms is the primary source of foods for households in this area. Detailed descriptions of the study area have been published previously ${ }^{(43)}$. This area was chosen because it had a sufficient number of rural schools, each separated by several kilometres, and due to its location in the Embu region where a cadre of highly trained personnel had carried out measurements previously and had excellent rapport with the community members ${ }^{(41)}$.

\section{Sampling}

Of the eighteen schools in an Embu subregion with 2600 households, twelve were chosen based on their size, location and accessibility for food delivery and ongoing assessments as explained in detail previously ${ }^{(43)}$. Schools were randomised into one of the three feeding groups or the Control group via a slightly restricted randomisation process such that the three large schools with more than one standard I classroom could not be randomised to the same feeding condition.

All the children enrolled in standard (grade) I (mean age $7 \cdot 1$ (SD 0.8) years) in September 1999 were considered for inclusion in the cohort II sample of the CNP study. Of the 635 children enrolled in standard I classes in September 1999, data from 216 children who had been held back from the previous year and were repeating standard I (and thus were already participating in the second year of the cohort I study) were excluded from the analysis. The other 419 children who were enrolled in standard I classes for the first time were considered for inclusion in the cohort II sample. Of these children, thirteen did not have data on term test scores available either due to absence from schools on the dates of test administration or failure to complete the tests. An additional forty-six standard I children aged above 9 years were excluded to compare children at similar physical and mental stages. Children excluded from the data collection process were fed along with their classmates when they were present at school. Data from 360 children were included in the present analysis (Fig. 1). 


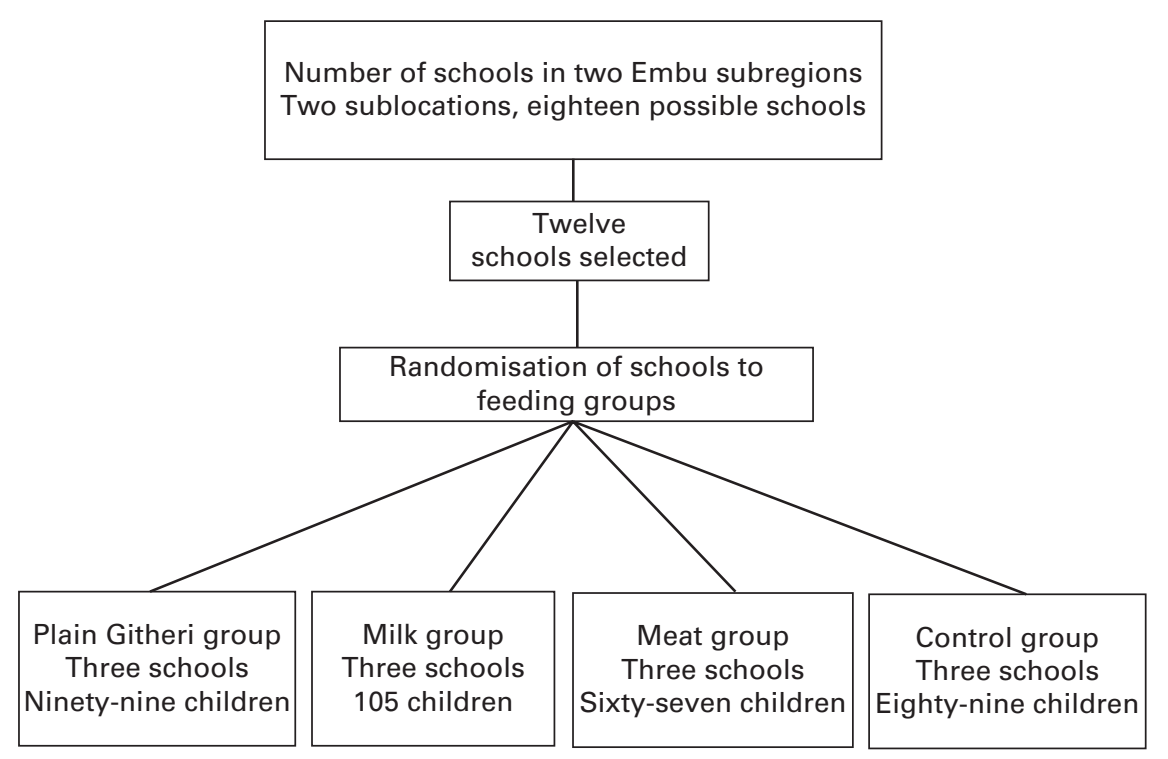

Fig. 1. Study flowchart.

\section{Snack design, preparation and delivery}

Children in the feeding group schools were given a midmorning snack. The Control group did not receive intervention feedings, but participated in all other aspects of the study. At the end of the study, the families in the Control group received one goat per household plus several male goats for the entire Control group.

Snacks were based on a local plant-based stew (githeri) with either added meat or a glass of whole ultra-heat-treated milk. The Plain Githeri group ( $n$ 99) received githeri prepared with $3.8 \mathrm{~g}$ of additional vegetable oil (Kimbo, Unilever, East African Industries), later found to have been fortified with $70 \mu \mathrm{g} \mathrm{retinol} / \mathrm{g}$ throughout the study period. The Milk group ( $n$ 105) received githeri plus a glass $(250 \mathrm{ml})$ of ultra-heattreated whole cows' milk. The Meat group ( $n$ 67) received githeri mixed with $85 \mathrm{~g}$ of ground beef containing $10-12 \%$ fat obtained frozen from a well-recognised, respected commercial supplier (Farmer's Choice). The Control group ( $n$ 89) received no supplemental feeding at school.

The three snacks were isoenergetic (approximately $1300 \mathrm{~kJ} /$ feeding) (Table 1). Snacks met approximately one-fifth of the recommended energy intake for children aged 6-9 years ${ }^{(44)}$.
Iodised salt was used. Stringent quality control measures were monitored by the analysis of the nutrient content of the test feedings two to three times per year. Detailed descriptions of the food preparation methods and quality control measures have been published previously ${ }^{(7,43,45)}$.

Snacks were delivered to each school and given to each child in a covered bowl labelled with their study number. A trained feeding assistant distributed the numbered bowls to each study child, observed the child during feeding, and collected and covered the bowls for measurement of leftovers in the test kitchen, by weighing solids using a beam balance and measuring the volume of milk. The adherence to consumption of the assigned snack by the children was very high; in $99.4 \%$ of the feeding sessions, the children consumed all the food provided $^{(46)}$. The feeding assistants were trained to observe the children during snack time to ensure that no sharing occurred and that spillage and unconsumed portions were recorded. If a child was absent, that child's uneaten portion was returned to the kitchen. Snacks were served at midmorning each day when the schools were in session over a period of 19 months from September 1999 to December 2001, a total of five school terms. School terms lasted for

Table 1. Nutrient content of cohort II school intervention snacks ${ }^{\star}$

\begin{tabular}{lccc}
\hline Serving size & $\begin{array}{c}\text { Githeri }+ \text { meat } \\
\text { (includes } 85 \mathrm{~g} \text { meat) }\end{array}$ & $\begin{array}{c}\text { Githeri }+ \text { milk } \\
100 \mathrm{~g}+250 \mathrm{ml} \text { milk }\end{array}$ & $\begin{array}{c}\text { Plain githeri } \\
230 \mathrm{~g}+3.8 \mathrm{~g} \text { oil }\end{array}$ \\
\hline Energy (kJ) & 1310 & 1310 & 1310 \\
Energy (kcal) & 313 & 313 & 313 \\
Total protein $(\mathrm{g})$ & 21.7 & 15.2 & 8.4 \\
Total Fe $(\mathrm{mg})$ & 2.94 & 1.57 & 3.93 \\
Available Fe $(\mathrm{mg})$ & 0.48 & 0.10 & 0.20 \\
Total $\mathrm{Zn}(\mathrm{mg})$ & 2.89 & 1.66 & 1.68 \\
Available Zn $(\mathrm{mg})$ & 0.44 & 0.38 & 0.23 \\
Vitamin $\mathrm{B}_{12}(\mu \mathrm{g})$ & 1.17 & 1.04 & 0.00 \\
Ca $(\mathrm{mg})$ & 21.3 & 306.0 & 33.8 \\
\hline
\end{tabular}

${ }^{*}$ Adapted with permission from Neumann et al. ${ }^{(43)}$. 
3 months with a 1-month break between each term. No snacks were given during school vacations or holidays.

\section{End-term test scores}

At the end of each school term, all the students in each school were tested in Arithmetic, English, Kiswahili, Mother tongue (Kiembu), Science/Agriculture, Geography/Civics/Culture/ Religion, Arts/Crafts and Music. These zone-wide tests were standardised tests designed by the Kenyan Ministry of Education, with identical questions for each school. Test patterns were changed slightly from term to term by the Ministry of Education based on the curriculum. Question papers were distributed by the district and zonal offices of the Ministry of Education, and the tests were administered by the classroom teachers. The level of difficulty of the test content was increased during each term to capture new topics taught in the curriculum. For the present study, end-term test scores were collected and recorded for each child over five successive terms from September 1999 to December 2000 from records in Head Teacher's office in each school. The maximum number of points in each individual academic subject test was 50, with one point per correct answer. The maximum possible total score in all the term examinations was a sum of 350 points from tests of seven individual academic subjects. Test scores obtained in term 1 were treated as baseline scores for the study children.

\section{Socio-economic status}

Data on the socio-economic status (SES) of the participating households were collected through interviews with household heads at baseline. The details of the SES scale and items used in the scale have been published previously, and the SES scale and items were created in consultation with the Kenyan Central Bureau of Statistics, one of the best-known and highly respected statistical groups in Kenya, with input from local leaders and household members ${ }^{(41,43)}$. The scale was used in a previous study carried out in this region ${ }^{(41)}$.

\section{Maternal literacy and educational attainment}

Maternal literacy ( $n$ 305) was assessed by testing the ability of each child's mother to read and comprehend passages of text from graded local Kiembu school textbooks selected to reflect different levels of difficulty. The tests were administered in either Kiembu, the predominant local spoken language $(92.9 \%)$, or English $(7 \cdot 1 \%)$, based on the participant's preference. The test score was equal to the total number of pages read aloud for which two of three questions were answered correctly. The cognitive assessment team that carried out the literacy tests consisted of three local women trained by a psychologist and child development expert, who had worked in Kenya in the NCRSP field study with the same field staff. The team was supervised by the Kenyan project psychologist who had a Master's degree and interacted frequently with the field staff, reviewed data collection techniques and helped with quality control. For quality control purposes, $10 \%$ of the mothers were tested simultaneously by two testers. There was perfect agreement between the scores recorded by each of the testers in these cases ${ }^{(47)}$. Periodically, the psychologist/child development expert travelled to Kenya to review data collection procedures and quality. Information regarding maternal school grade attainment was included in the household SES questionnaire.

\section{School attendance}

The total number of school days per term that each child attended school was recorded. Attendance information was obtained from each classroom teacher's daily records as well as from the daily intervention feeding logs maintained by the feeding assistant at each school.

\section{Food intake}

The home food intake of the children was measured through $24 \mathrm{~h}$ semi-quantitative recall interviews with their mothers or caretakers. At baseline, three recall interviews were conducted (each 1 week apart), and the intake values for the 3 weeks were averaged to obtain values for the baseline intake of energy and other nutrients. Subsequent recall measures were recorded every 2 months over a 16-month period. Average home food intake was calculated across the eight single post-baseline recall visits. The recalls were administered at the homes of the children by trained enumerators using household measures and samples of local foods (i.e. fruits and vegetables) to assess size. This method, energy and nutrient intake calculations, and quality control measures have been described in detail previously ${ }^{(7,43,48)}$. For the calculation of changes in average individual nutrient intake from baseline to follow-up, home food intake data collected at follow-up and baseline and nutrient estimates associated with the different snack types at follow-up were used. Follow-up home food nutrient estimates for the study children were based on eight recalls of daily intake over a four-term period from September 1999 to December 2000.

\section{Other covariates}

Data regarding morbidity, anthropometry, children's cognitive development measured using Raven's Progressive Matrices (RPM), verbal meaning, and arithmetic tests and physical activity were collected using methods described in previous publications ${ }^{(43,47,49)}$.

\section{Protection of human research participants}

The present study was conducted according to the guidelines laid down in the Declaration of Helsinki, and all procedures involving human research participants were approved by the Human Subjects Protection Committee of the University of California, Los Angeles, the Ethics Committee of the University of Nairobi, School of Medicine, and the Office of the President in Kenya. Verbal informed consent from parents and assent from children were obtained. Verbal consent was witnessed 
and formally recorded. The investigators also obtained community permissions via community meetings. Verbal permission was obtained from the Provincial Office of Education, the Director of the Zonal Office of Education, and the Head Teacher (principal) of each school and from each classroom teacher to obtain the end-term test scores of the children.

\section{Statistical analysis}

Differences in baseline characteristics between the feeding groups were determined using ANOVA. If overall differences were significant, then pairwise differences were examined to determine which groups were different from each other.

Outcome variables were the test scores in end-term academic tests of seven subjects (English, Arithmetic, Kiswahili, Kiembu, science, geography, arts) and the total test scores. The total score for each child was calculated by adding the test scores in seven subjects in each term. In ANOVA tests of baseline test scores, all the available data were used. A child was considered to have missing data for the total test score in a given term if he or she was missing a score for any academic subject test in an end-term examination.

Longitudinal models ${ }^{(50)}$ were fit to test scores using the Statistical Analysis Systems mixed procedure version 9 (SAS Institute, Inc.) with an unstructured covariance matrix and time $\times$ school interaction model with a separate mean for each school in each term. Additional predictor variables included maternal literacy and highest school grade attained, household SES, children's school attendance, children's RPM scores, school, children's baseline age, sex, morbidity score, malaria status, anaemia status, anthropometry and baseline energy intake. Differences were considered statistically significant at $P<0 \cdot 05$. As there were three schools in each study group, estimates of the study group means in a given term were estimated as the average of the means of the three schools in that term.

For each child, average follow-up nutrient intake was calculated by averaging the intake recorded at eight post-baseline recall visits including the contributions of the Meat, Milk and Plain Githeri feedings. To identify the possible effects of nutrients on test scores, average nutrient intake and average nutrient intake $\times$ time interaction were used as predictors in the previous models with separate analyses being carried out for each nutrient of interest and test scores in each subject. If the coefficient of the average nutrient intake $\times$ time interaction is positive, then increased nutrient intake is associated with increased changes in test scores from term 5 -term 1 . To make this interaction more interpretable, we subtracted the estimated change in test scores (term 5 -term 1) for a hypothetical student at the 90th percentile of the average follow-up nutrient intake distribution from the estimated change in test scores (term 5-term 1) for a hypothetical student at the 10th percentile of the average follow-up nutrient intake distribution, holding all other predictors constant.

\section{Results}

\section{Baseline findings}

At baseline, there were no significant differences between the feeding groups for most of the variables, except for years of school completed by the mothers, which was highest in the Control group (Table 2). Across the feeding groups, the average of maternal literacy was between the 7 th and 9 th grade levels, with individual levels ranging from 0 to 12 th grades. At baseline, baseline maternal literacy above the 8th grade when compared with maternal literacy below the 8th grade was associated with higher end-term test scores in every academic subject and total test scores $(P<0 \cdot 001)$. However, there were no significant differences between the feeding groups for maternal literacy at baseline.

The baseline home intake of energy, protein and folate was significantly higher in children in the Plain Githeri group than in those in the Milk group $(P<0.05)$ (Table 3 ). The intake of available $\mathrm{Fe}$ was significantly higher in children in the Plain Githeri group than in those in the Milk and Control groups $(P<0 \cdot 05)$.

Table 2. Baseline characteristics by study group

(Mean values and standard deviations)

\begin{tabular}{|c|c|c|c|c|c|c|c|c|}
\hline & Mean & SD & Mean & SD & Mean & SD & Mean & SD \\
\hline Male sex (\%) & \multicolumn{2}{|c|}{39.0} & \multicolumn{2}{|c|}{51.0} & \multicolumn{2}{|c|}{54.0} & \multicolumn{2}{|c|}{$45 \cdot 0$} \\
\hline SES (total score) & $88 \cdot 1$ & $18 \cdot 9$ & 87.4 & $29 \cdot 6$ & 88.7 & 14.9 & $85 \cdot 9$ & $20 \cdot 3$ \\
\hline $\begin{array}{l}\text { School attendance } \\
\text { (percentage of days school open) }\end{array}$ & $83 \cdot 0$ & $15 \cdot 0$ & 83.0 & $13 \cdot 0$ & $86 \cdot 0$ & $14 \cdot 0$ & $84 \cdot 0$ & $17 \cdot 0$ \\
\hline Child RPM test scores & $17 \cdot 4$ & 1.96 & 17.5 & 2.54 & $17 \cdot 2$ & $2 \cdot 39$ & $17 \cdot 4$ & $2 \cdot 30$ \\
\hline WAZ & -1.51 & 0.96 & -1.58 & $2 \cdot 12$ & -1.48 & 0.81 & -1.38 & 0.99 \\
\hline HAZ & -1.54 & 0.89 & -1.41 & $1 \cdot 13$ & -1.56 & 0.80 & -1.38 & 1.03 \\
\hline MUAC (cm) & $15 \cdot 56$ & $1 \cdot 12$ & $15 \cdot 69$ & 1.04 & $15 \cdot 68$ & 1.00 & 15.56 & 0.95 \\
\hline TSF $(\mathrm{mm})$ & $5 \cdot 79$ & 1.98 & 5.92 & 1.79 & $6 \cdot 13$ & 1.60 & $5 \cdot 84$ & 1.57 \\
\hline
\end{tabular}

SES, socio-economic status; RPM, Raven's Progressive Matrices; WAZ, weight-for-age $z$-score; HAZ, height-for-age $z$-score; MUAC, mid-upper arm circumference; TSF, triceps skinfold.

* Mean value was significantly different from that of the Meat group $(F(3,281)=3 \cdot 28, P=0.021$; ANOVA tests $)$ 
Table 3. Baseline home food intake, follow-up (FU) intake including school snack, and change in nutrient intake from baseline to FU by study group\|ף

(Mean values and standard deviations)

\begin{tabular}{|c|c|c|c|c|c|c|c|c|}
\hline \multirow[b]{2}{*}{ Nutrient } & \multicolumn{2}{|c|}{ Plain Githeri ( $n$ 99) } & \multicolumn{2}{|c|}{ Milk ( $n$ 105) } & \multicolumn{2}{|c|}{ Meat $(n 67)$} & \multicolumn{2}{|c|}{ Control ( $n$ 89) } \\
\hline & Mean & SD & Mean & SD & Mean & SD & Mean & SD \\
\hline \multicolumn{9}{|l|}{ Energy } \\
\hline Baseline $^{\star *}(\mathrm{~kJ})$ & $7463.9^{*}$ & $3032 \cdot 3$ & $6243 \cdot 6$ & $2135 \cdot 0$ & $6689 \cdot 0$ & $2818 \cdot 2$ & $6489 \cdot 8$ & 2923.2 \\
\hline Baseline $^{\star \star}(\mathrm{kcal})$ & $1783 \cdot 9^{*}$ & $724 \cdot 7$ & $1492 \cdot 3$ & $510 \cdot 3$ & $1598 \cdot 7$ & 673.6 & $1551 \cdot 1$ & $698 \cdot 7$ \\
\hline FU†† (kJ) & 8461.0 & $1155 \cdot 6$ & 8278.6 & $1324 \cdot 4$ & $8266 \cdot 8$ & $1400 \cdot 8$ & $7526 \cdot 5$ & $1455 \cdot 2$ \\
\hline FU†† (kcal) & $2022 \cdot 2$ & $276 \cdot 2$ & $1978 \cdot 6$ & $316 \cdot 6$ & $1975 \cdot 8$ & 334.8 & 1798.9 & 347.8 \\
\hline 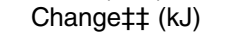 & $1013 \cdot 3 \dagger$ & $3122 \cdot 4$ & $2048 \cdot 1 \dagger$ & $2388 \cdot 0$ & $1573.4 \dagger$ & $708 \cdot 7$ & 1033.3† & $2903 \cdot 6$ \\
\hline Change $\ddagger$ (kcal) & $242 \cdot 2 \dagger$ & $746 \cdot 3$ & $489.5 t$ & 570.7 & $376.1 \dagger$ & 704.5 & $247.0 \dagger$ & 694.0 \\
\hline \multicolumn{9}{|l|}{ Energy/kg body weight } \\
\hline Baseline $(\mathrm{kJ} / \mathrm{kg})$ & $400 \cdot 33^{*}$ & $176 \cdot 56$ & 328.78 & 114.52 & 349.41 & $142 \cdot 63$ & 353.42 & $168 \cdot 70$ \\
\hline Baseline (kcal/kg) & $95 \cdot 68^{*}$ & $42 \cdot 20$ & 78.58 & $27 \cdot 37$ & 83.51 & 34.09 & 84.47 & $40 \cdot 32$ \\
\hline FU $(\mathrm{kJ} / \mathrm{kg})$ & $416 \cdot 89$ & 72.47 & $397 \cdot 10$ & 74.85 & 395.68 & 73.81 & 368.48 & 83.01 \\
\hline $\mathrm{FU}(\mathrm{kcal} / \mathrm{kg})$ & 99.64 & $17 \cdot 32$ & 94.91 & $17 \cdot 89$ & 94.57 & $17 \cdot 64$ & 88.07 & $19 \cdot 84$ \\
\hline Change $(\mathrm{kJ} / \mathrm{kg})$ & 16.95 & $170 \cdot 21$ & $66.90 \dagger$ & $119 \cdot 50$ & $47 \cdot 28 \dagger$ & $146 \cdot 61$ & $19 \cdot 46$ & $161 \cdot 29$ \\
\hline Change (kcal/kg) & 4.05 & 40.68 & $15 \cdot 99+$ & 28.56 & $11.30 \dagger$ & 35.04 & 4.65 & 38.55 \\
\hline \multicolumn{9}{|l|}{ Protein $(\mathrm{g})$} \\
\hline Baseline & $61 \cdot 70^{*}$ & $30 \cdot 78$ & 47.97 & $18 \cdot 24$ & 57.54 & 27.73 & 51.86 & $25 \cdot 38$ \\
\hline FU & $61 \cdot 85$ & $10 \cdot 67$ & $62 \cdot 19$ & 12.45 & 74.66 & $12 \cdot 72$ & 54.93 & $13 \cdot 36$ \\
\hline Change & -0.08 & $32 \cdot 87$ & $14.49 \dagger$ & $20 \cdot 54$ & $16 \cdot 94 \dagger$ & 28.87 & 3.01 & $25 \cdot 50$ \\
\hline \multicolumn{9}{|l|}{ Total Fe (mg) } \\
\hline Baseline & $18 \cdot 42^{*} \ddagger$ & $8 \cdot 70$ & 14.48 & $7 \cdot 29$ & $15 \cdot 37$ & 7.49 & 14.39 & $7 \cdot 16$ \\
\hline FU & $21.02 \ddagger$ & 4.23 & $18 \cdot 65$ & 4.42 & $21 \cdot 18 \ddagger$ & 4.62 & $18 \cdot 37$ & 4.55 \\
\hline Change & $2.62 \dagger$ & $9 \cdot 20$ & $4 \cdot 24 \dagger$ & $7 \cdot 72$ & $5.83 \dagger$ & 7.87 & $3.98 \dagger$ & $7 \cdot 67$ \\
\hline \multicolumn{9}{|l|}{ Available Fe (mg) } \\
\hline Baseline & $1 \cdot 38^{*} \ddagger$ & 0.83 & 1.03 & 0.51 & $1 \cdot 30$ & 0.75 & 1.05 & 0.55 \\
\hline $\mathrm{FU}$ & 1.63 & 0.40 & $1.48 \ddagger$ & 0.38 & $2 \cdot 01 \ddagger$ & 0.44 & 1.58 & 0.42 \\
\hline Change & $0.23 \dagger$ & 0.86 & $0.46 \dagger$ & 0.60 & $0.69 \dagger$ & 0.78 & $0.53 \dagger$ & 0.65 \\
\hline \multicolumn{9}{|l|}{ Total Zn (mg) } \\
\hline Baseline & $9 \cdot 42^{*} \ddagger$ & $4 \cdot 67$ & $7 \cdot 29$ & 2.98 & $8 \cdot 39$ & $4 \cdot 28$ & $7 \cdot 72$ & 3.76 \\
\hline FU & $9 \cdot 82$ & 1.60 & $9 \cdot 72$ & 1.90 & 11.97 & 2.05 & 8.78 & 2.06 \\
\hline Change & 0.35 & 4.99 & $2 \cdot 47 \dagger$ & $3 \cdot 36$ & $3.56 \dagger$ & 4.56 & $1.06 \dagger$ & $3 \cdot 76$ \\
\hline \multicolumn{9}{|l|}{ Basal Zn (mg) } \\
\hline Baseline & 1.00 & 0.45 & 0.85 & 0.35 & 0.99 & 0.42 & 0.93 & 0.46 \\
\hline FU & 1.06 & $0 \cdot 18$ & $1 \cdot 16$ & 0.22 & 2.09 & 0.21 & 0.94 & 0.22 \\
\hline Change & 0.06 & 0.49 & $0.31 \dagger$ & 0.40 & $1 \cdot 10 \dagger$ & 0.45 & 0.01 & 0.46 \\
\hline \multicolumn{9}{|l|}{ Normative Zn (mg) } \\
\hline Baseline & 0.99 & 0.45 & 0.84 & 0.33 & 0.98 & 0.41 & 0.92 & 0.46 \\
\hline FU & 1.06 & $0 \cdot 18$ & $1 \cdot 15$ & 0.21 & 1.98 & 0.21 & 0.93 & 0.22 \\
\hline Change & 0.07 & 0.49 & $0.31 \dagger$ & 0.38 & $1.00 \dagger$ & 0.44 & 0.01 & 0.46 \\
\hline \multicolumn{9}{|l|}{ Vitamin $B_{12}(\mu \mathrm{g})$} \\
\hline Baseline & 0.39 & 0.40 & 0.40 & 0.39 & 0.28 & 0.27 & 0.38 & 0.31 \\
\hline FU & 0.31 & 0.24 & 1.36 & 0.40 & 1.61 & 0.30 & 0.42 & 0.31 \\
\hline Change & $-0.05 \dagger$ & 0.34 & $0.93 \dagger$ & 0.38 & $1.28 \dagger$ & 0.30 & 0.05 & 0.38 \\
\hline \multicolumn{9}{|l|}{ Folate $(\mu \mathrm{g})$} \\
\hline Baseline & $671.63^{*}$ & $406 \cdot 30$ & $501 \cdot 10$ & 271.05 & $758 \cdot 07 \ddagger$ & $416 \cdot 58$ & $608 \cdot 17$ & 378.07 \\
\hline FU & $604.70 \ddagger$ & $158 \cdot 82$ & 534.34 & $147 \cdot 30$ & 584.91‡ & $155 \cdot 36$ & 530.98 & 142.43 \\
\hline Change & $-70 \cdot 84$ & $414 \cdot 39$ & $37 \cdot 37$ & $270 \cdot 15$ & $-178.38 \dagger$ & $406 \cdot 15$ & $-77 \cdot 86$ & 375.91 \\
\hline \multicolumn{9}{|l|}{ Vitamin $B_{6}(\mathrm{mg})$} \\
\hline Baseline & $2 \cdot 37^{\star} \neq \S$ & 1.35 & $1 \cdot 85$ & 0.96 & 1.80 & 0.95 & 1.89 & $1 \cdot 14$ \\
\hline FU & $2 \cdot 28 \ddagger$ & 0.45 & $2 \cdot 33 \ddagger$ & 0.45 & $2 \cdot 21$ & 0.45 & $2 \cdot 18$ & 0.44 \\
\hline Change & -0.10 & $1 \cdot 36$ & $0.48 \dagger$ & 1.00 & $0.40 \dagger$ & 1.06 & $0.29 \dagger$ & $1 \cdot 13$ \\
\hline \multicolumn{9}{|l|}{ Riboflavin (mg) } \\
\hline Baseline & $1.06^{*}$ & 0.45 & 0.87 & 0.35 & 0.96 & 0.40 & 0.97 & 0.45 \\
\hline FU & $1 \cdot 10$ & $0 \cdot 18$ & $1.51 \ddagger$ & 0.20 & $1 \cdot 18 \ddagger$ & 0.19 & $1 \cdot 11$ & 0.21 \\
\hline Change & 0.04 & 0.45 & $0.63 \dagger$ & 0.37 & $0.22 \dagger$ & 0.40 & $0.13 \dagger$ & 0.44 \\
\hline
\end{tabular}

* Mean values were significantly different from those of the Milk group $(P<0.05$; ANOVA).

† Mean values were significantly different from own baseline value $(P<0.05$; paired $t$ test).

$\ddagger$ Mean values were significantly different from those of the Control group $(P<0.05 ; \mathrm{ANOVA})$.

$\S$ Mean values were significantly different from those of the Meat group $(P<0.05$; ANOVA).

$\|$ Comparisons of baseline means between the groups and FU means between the groups were made using ANOVA tests.

- Paired $t$ tests were used to assess the change in mean nutrient intake from baseline to FU for each of the groups. Change values were calculated for children with both baseline and FU values and thus may not exactly equal FU value minus baseline value due to missing data at either baseline or FU.

** Baseline nutrient intake values are the average of intake values recorded in three dietary recalls.

t†FU nutrient intake values are the average of eight dietary recalls over a 16-month period and include the nutrient values from the school snack.

¥ Changes in nutrient intake values were calculated from baseline and FU values. Values may not exactly equal the FU intake value minus the baseline intake value due to some missing FU intake data. 
Table 4. Baseline (term 1) end-term test scores by group (Mean values and standard deviations)

\begin{tabular}{|c|c|c|c|c|c|c|c|c|}
\hline & \multicolumn{2}{|c|}{ Plain Githeri ( $n$ 99) } & \multicolumn{2}{|c|}{ Milk ( $n$ 105) } & \multicolumn{2}{|c|}{ Meat $(n 67)$} & \multicolumn{2}{|c|}{ Control ( $n 89)$} \\
\hline & Mean & SD & Mean & SD & Mean & SD & Mean & SD \\
\hline Arithmetic & $32 \cdot 7^{\star}$ & $12 \cdot 6$ & $32 \cdot 4$ & $12 \cdot 2$ & $26 \cdot 9$ & 14.5 & 30.4 & $13 \cdot 2$ \\
\hline English & $33 \cdot 2^{*} \dagger$ & $14 \cdot 0$ & $31.9^{*}$ & $10 \cdot 8$ & $22 \cdot 6$ & $12 \cdot 5$ & 27.5 & $13 \cdot 4$ \\
\hline Kiembu & $34 \cdot 5^{\star} \dagger$ & $12 \cdot 6$ & 30.7 & $12 \cdot 6$ & $26 \cdot 5$ & $15 \cdot 4$ & 27.4 & $12 \cdot 0$ \\
\hline Kiswahili & $33 \cdot 0^{*} \ddagger$ & $13 \cdot 4$ & $26 \cdot 5$ & $13 \cdot 2$ & $25 \cdot 2$ & $14 \cdot 0$ & $29 \cdot 1$ & $12 \cdot 0$ \\
\hline Geography & $36 \cdot 6$ & $11 \cdot 1$ & $35 \cdot 1$ & $11 \cdot 0$ & $33 \cdot 0$ & $10 \cdot 8$ & $36 \cdot 4$ & $12 \cdot 4$ \\
\hline Science & $42 \cdot 3^{*} \dagger$ & 7.63 & 38.4 & $10 \cdot 1$ & $35 \cdot 2$ & $14 \cdot 0$ & $35 \cdot 0$ & $11 \cdot 0$ \\
\hline Arts & $39 \cdot 3^{*} \dagger$ & $7 \cdot 79$ & $36 \cdot 8$ & 9.02 & 32.9 & $12 \cdot 8$ & $34 \cdot 2$ & $10 \cdot 7$ \\
\hline Combined score & $245 \cdot 2^{*}$ & 74.7 & $229 \cdot 4^{*}$ & 67.9 & $192 \cdot 5$ & 88.2 & $215 \cdot 6$ & $79 \cdot 7$ \\
\hline
\end{tabular}

* Mean values were significantly different from those of the Meat group $(P<0.05$; ANOVA test; pairwise $t$ test). † Mean values were significantly different from those of the Control group $(P<0.05$; ANOVA test; pairwise $t$ test). $\ddagger$ Mean value was significantly different from that of the Milk group $(P<0.05$; ANOVA test; pairwise $t$ test).

Baseline test scores (zone-wide end-term scores in the term before the start of the feeding intervention) indicated that the Plain Githeri group scored significantly higher than the Meat group and the Control group in English, Kiembu, Science and Arts and significantly higher than the Milk and Meat groups in Kiswahili (Table 4). The Plain Githeri group had significantly higher scores than the Meat group in Arithmetic and significantly higher total test scores. The Milk group had significantly higher scores than the Meat group in English and significantly higher total combined scores.

\section{Intervention results}

In the total sample, attendance was a significant predictor of end-term test scores; however, no significant trends towards greater attendance were observed in the Meat and the Milk groups over the study period. For all the feeding groups, maternal literacy was a significant predictor of total end-term test scores in all the academic subjects except in Arts. Children with mothers with low baseline literacy levels (below 8th grade) showed significantly greater improvements (term 5 - term 1) than those with mothers with high baseline maternal literacy levels (above 8th grade) $(P<0 \cdot 05)$.

\section{Change in test scores compared with baseline test scores}

Comparisons of the final term test scores (term 5) and baseline test scores revealed significant improvements in the test scores of the Meat group in six subjects compared with the baseline test scores $(P<0.05)$ (Fig. 2). The Milk group showed significant improvements in test scores in five of the eight scores. The test scores of the Plain Githeri and Control groups in Arts in term 5 were significantly better than those at baseline, but lower than those at baseline in the other academic subjects. All the groups had lower test scores in Science in term 5 than at baseline.

\section{Changes in nutrient intake compared with baseline values}

Energy intake increased for all the four groups (Table 3). In the Meat and Milk groups, the intake of all nutrients improved significantly. However, in the Milk, Plain Githeri and Control groups, intake averaged below the recommended intake levels for available $\mathrm{Fe}$ (estimated average requirement $=4 \cdot 1$ $\mathrm{mg} / \mathrm{d}$ for children aged $4-8$ years) and $\mathrm{Zn}$ (estimated average requirement $=4.0 \mathrm{mg} / \mathrm{d}$ for children aged $4-8$ years $)^{(44)}$. The intake of vitamin $\mathrm{B}_{12}$ in the Control and Plain Githeri groups was below the recommended levels (estimated average requirement $=1 \cdot 0 \mu \mathrm{g}$ for children aged $4-8$ years $)^{(44)}$.

\section{Changes in the test scores of each feeding group compared with changes in those of the Control group}

Because the intervention groups had to be compared with the Control group also, differences (term 5-term 1) in the mean test scores of each feeding group minus differences in the mean test scores of the Control group were calculated (Table 5). Children in the Meat group, and to a lesser extent those in the Milk group, exhibited greater positive changes in test scores compared with those in the Plain Githeri and Control groups. The Meat group showed significant improvements in test scores compared with the Control group in six of the seven subjects (Arithmetic, English, Kiembu, Kiswahili, Geography and Arts) and in the overall total test scores. The Milk group showed significant improvements in test scores compared with the Control group in five subjects (English, Kiswahili, Geography and Science) and in the overall total test scores. The changes in the test scores of the Plain Githeri group were not significantly different from those in the test scores of the Control group in any academic subject.

\section{Comparisons between the groups}

Inter-group comparisons for change in mean test scores from baseline to term 5 in each academic subject showed that changes in the total test scores of the Meat and Milk groups were significantly greater than those in the total test scores of the Control group (Table 5). The Meat group was significantly higher in test scores than the Plain Githeri group in six subjects (Arithmetic, English, Kiembu, Kiswahili, Geography and Arts) and in the total test scores, and it showed significant improvements in test scores compared 


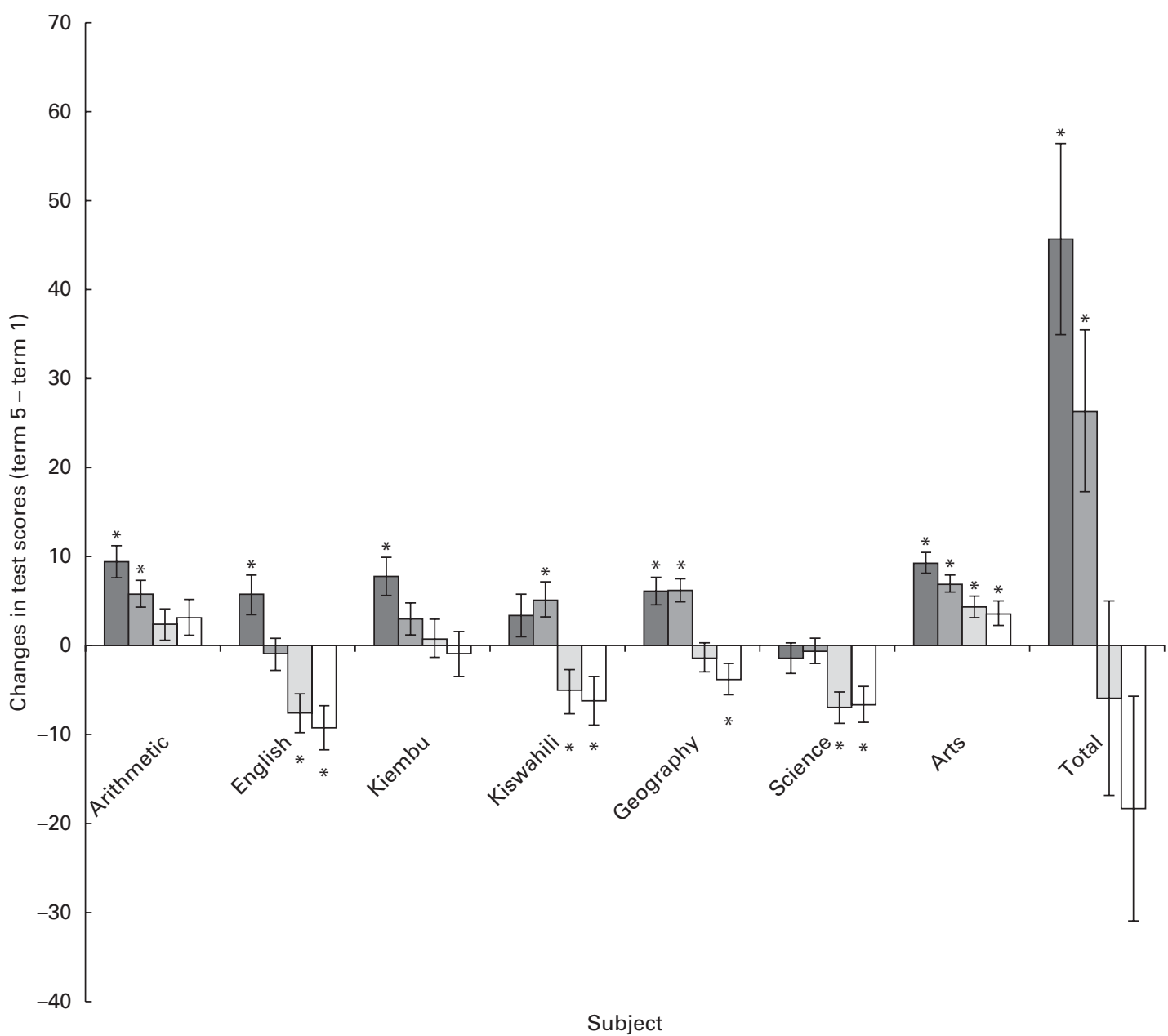

Fig. 2. Change in test scores by group compared with baseline test scores (term $5-$ term 1). Values show the change in test scores (term $5-$ term 1 ) in each academic subject. Values are means, with their standard errors represented by vertical bars. * Mean values were significantly different between own term 5 and term 1 (baseline) scores $(P<0.05)$. $\square$, Meat; $\square$, milk; $\square$, plain Githeri; $\square$, control.

with the Control group in all the subjects except in Science. The changes in the test scores of the Milk group were significantly greater than those in the test scores of the Plain Githeri and Control groups in English, Kiswahili, Geography and
Science. Compared to each other, the Meat and Milk groups were only significantly different for English scores, with the Meat group showing a significant improvement compared to the Milk group.

Table 5. Pairwise comparisons of changes in test scores (term 5 (T5) mean - term 1 (T1) mean)†‡ (Mean values with their standard errors)

\begin{tabular}{|c|c|c|c|c|c|c|c|c|c|c|c|c|}
\hline & \multicolumn{2}{|c|}{ Meat-Control } & \multicolumn{2}{|c|}{ Meat-Milk } & \multicolumn{2}{|c|}{$\begin{array}{l}\text { Meat-Plain } \\
\text { Githeri }\end{array}$} & \multicolumn{2}{|c|}{ Milk-Control } & \multicolumn{2}{|c|}{ Milk-Plain Githeri } & \multicolumn{2}{|c|}{$\begin{array}{c}\text { Plain } \\
\text { Githeri-Control }\end{array}$} \\
\hline & $\mathrm{T} 5-\mathrm{T} 1$ & SE & $\mathrm{T} 5-\mathrm{T} 1$ & SE & $\mathrm{T} 5-\mathrm{T} 1$ & SE & $\mathrm{T} 5-\mathrm{T} 1$ & SE & $\mathrm{T} 5-\mathrm{T} 1$ & SE & $\mathrm{T} 5-\mathrm{T} 1$ & SE \\
\hline Arithmetic & $5 \cdot 41^{\star}$ & $2 \cdot 66$ & $3 \cdot 60$ & $2 \cdot 28$ & $6 \cdot 18^{\star}$ & 2.50 & $1 \cdot 82$ & 2.49 & $2 \cdot 59$ & $2 \cdot 30$ & -0.77 & $2 \cdot 67$ \\
\hline English & $14 \cdot 3^{\star}$ & $3 \cdot 34$ & $6 \cdot 58^{*}$ & $2 \cdot 87$ & $12 \cdot 5^{\star}$ & $3 \cdot 14$ & $7 \cdot 73^{\star}$ & $3 \cdot 10$ & $5 \cdot 89^{\star}$ & $2 \cdot 87$ & 1.84 & $3 \cdot 33$ \\
\hline Kiembu & $7 \cdot 71^{*}$ & $3 \cdot 24$ & 4.73 & $2 \cdot 78$ & $6 \cdot 03^{*}$ & 3.05 & 2.98 & 3.02 & $1 \cdot 29$ & $2 \cdot 80$ & 1.68 & $3 \cdot 25$ \\
\hline Kiswahili & $8 \cdot 29^{*}$ & 3.63 & -2.08 & $3 \cdot 10$ & $7 \cdot 11^{*}$ & 3.41 & $10 \cdot 4^{\star}$ & 3.39 & $9 \cdot 19^{*}$ & $3 \cdot 13$ & $1 \cdot 17$ & 3.64 \\
\hline Geography & $9 \cdot 31^{*}$ & $2 \cdot 37$ & -0.03 & 2.03 & $7 \cdot 00^{\star}$ & $2 \cdot 24$ & $9 \cdot 35^{\star}$ & $2 \cdot 22$ & $7 \cdot 03^{*}$ & $2 \cdot 07$ & $2 \cdot 32$ & $2 \cdot 40$ \\
\hline Science & $4 \cdot 28$ & $2 \cdot 61$ & -1.04 & $2 \cdot 22$ & $4 \cdot 81$ & 2.45 & $5 \cdot 33^{*}$ & 2.45 & $5 \cdot 85^{\star}$ & $2 \cdot 28$ & -0.53 & $2 \cdot 64$ \\
\hline Arts & $5 \cdot 26^{\star}$ & 1.82 & 2.42 & 1.56 & $4 \cdot 67^{\star}$ & $1 \cdot 71$ & $2 \cdot 85$ & $1 \cdot 71$ & $2 \cdot 25$ & 1.59 & 0.59 & 1.84 \\
\hline Total & $57 \cdot 5^{\star}$ & $16 \cdot 3$ & $18 \cdot 0$ & $13 \cdot 9$ & $44 \cdot 8^{\star}$ & $15 \cdot 22$ & $39 \cdot 4^{\star}$ & $15 \cdot 3$ & $26 \cdot 8$ & $14 \cdot 1$ & $12 \cdot 7$ & $16 \cdot 4$ \\
\hline
\end{tabular}

${ }^{*} P<0.05$

† Values are the difference in changes in mean test scores (T5 - T1) between the studied groups.

$\ddagger$ Note: End-term tests administered in different terms are not identical, so a decrease in test scores does not denote a decrease in knowledge. Test content had an increasing level of difficulty each term, meant to capture new topics taught in the curriculum. 


\section{Effects of nutrient intake on changes in test scores}

Of the twelve nutrients tested, seven nutrients were significant contributors to the change in test scores (Table 6). A positive outcome represents a better performance in the school test by the 90th percentile group (high intake) than by the 10th percentile group (low intake). A negative outcome indicates that the lower-intake group outperformed the high-intake group. The intake of $\mathrm{Fe}$ and vitamin $\mathrm{B}_{12}$ predicted the largest change in test scores in three subjects each, although the effect of vitamin $\mathrm{B}_{12}$ on test scores in Science was negative. The change in test scores in English and Science was not related to nutrient intake. Micronutrient intake associated with the meat and milk snacks significantly predicted increases in test scores in six of the eight test scores over time.

Increases in test scores associated with nutrient intake were observed for Arithmetic, Kiembu, Kiswahili, Geography and Arts, and there were increases in the total test scores. Test scores in English and Science were not related to the intake of the nutrients listed in Table 6, with the exception of vitamin $\mathrm{B}_{12}$, which had a negative effect on the test scores in Science. Higher intake of Fe predicted higher test scores in Kiembu, Kiswahili and Geography and higher total test scores. Higher intake of vitamin $\mathrm{B}_{12}$ predicted better performance in Arithmetic, Geography and Arts, but worse performance in Science. Five nutrients contributed significantly to the change in test scores in Kiembu and Geography. The change in test scores in Arithmetic was predicted by the intake of folate and vitamin $\mathrm{B}_{12}$. Test scores in both Kiembu and Kiswahili were significantly affected by higher intake of folate, Fe and available Fe. Test scores in Kiembu were also significantly predicted by energy intake per $\mathrm{kg}$ body weight and $\mathrm{Zn}$ intake. Test scores in Geography improved significantly with higher intake of Fe, energy per kg of body weight, vitamin $\mathrm{B}_{12}, \mathrm{Zn}$ and riboflavin. Test scores in both Geography and Kiembu increased with higher intake of five different nutrients. Test scores in Arts improved with the intake of folate, available $\mathrm{Fe}$ and vitamin $\mathrm{B}_{12}$. Increases in total combined scores were significantly associated with the intake of folate, $\mathrm{Fe}$ and energy per body weight. The intake of basal $\mathrm{Zn}$, normative $\mathrm{Zn}$, energy, vitamin $\mathrm{B}_{6}$ and protein was not significantly related to changes in test scores.

\section{Discussion}

The intake of a school snack containing ASF (meat or milk) significantly predicted improvement in test scores over time. The snacks served in the CNP study were isoenergetic, but targeted different existing nutrient gaps in Kenyan school children's diet, mainly animal source protein, available Zn, available $\mathrm{Fe}$ and vitamin $\mathrm{B}_{12}$. The present study is the first cluster-randomised, controlled feeding intervention study to demonstrate the impact of ASF on children's academic performance. Meat, and to a slightly lesser extent milk, supplementation resulted in significantly better test score improvements in key academic subjects (Arithmetic, English, Kiswahili and Geography) and total test scores compared with the other groups.

Data obtained from cohort I, which cohort II replicates, indicate that there were no significant changes in home food intake over the 2 years of the study, except in the energy and protein intake of children in the Meat group at home ${ }^{(51)}$. This may be due to their improved appetite and their increased activity levels. The meat snack had the greatest amount of bioavailable Fe and Zn, which are known to improve appetite. Children in the Meat group also exhibited significant increases in physical activity levels and lean body mass ${ }^{(52-54)}$.

The improvements in test scores observed in the Meat group are impressive, given that at baseline the Meat group had the lowest test scores among all the groups in all but one academic subject and lowest total test scores. Yet, following the intervention feedings, the Meat group had the highest total test scores and also obtained the highest test scores in several academic subjects. The Milk group obtained higher test scores than the other groups in certain academic subjects (Table 5); however, in no academic subject were the scores of the Milk group significantly higher than those of the Meat

Table 6. Change in test scores (term 5 - term 1) due to differential nutrient intake (that of a child at the 90th percentile nutrient intake minus that of the child at the 10th percentile nutrient intake)†

\begin{tabular}{|c|c|c|c|c|c|c|c|c|}
\hline Nutrients & Arithmetic & English & Kiembu & Kiswahili & Geography & Science & Arts & Total \\
\hline Energy & 0.57 & 0.55 & 4.00 & 2.49 & 3.02 & 0.74 & 1.45 & 10.98 \\
\hline Energy/kg & 1.19 & $3 \cdot 19$ & $6 \cdot 14^{*}$ & 3.04 & $5 \cdot 26^{*}$ & 1.88 & 1.91 & $20 \cdot 71^{*}$ \\
\hline Protein & $3 \cdot 37$ & $3 \cdot 01$ & 4.94 & $4 \cdot 21$ & 2.95 & $1 \cdot 34$ & $2 \cdot 32$ & $17 \cdot 74$ \\
\hline $\mathrm{Fe}$ & $3 \cdot 33$ & $4 \cdot 33$ & $8 \cdot 40^{*}$ & $7 \cdot 57^{\star}$ & $3 \cdot 78^{*}$ & $2 \cdot 18$ & $2 \cdot 18$ & $27 \cdot 67^{*}$ \\
\hline Available Fe & 3.53 & 3.99 & $7 \cdot 53^{*}$ & $8.06^{*}$ & $2 \cdot 86$ & $3 \cdot 28$ & $2.97^{*}$ & $20 \cdot 95$ \\
\hline $\mathrm{Zn}$ & 2.09 & $2 \cdot 19$ & $4 \cdot 34^{*}$ & $3 \cdot 86$ & $2 \cdot 66^{\star}$ & 0.84 & $1 \cdot 28$ & 14.93 \\
\hline Basal Zn & $4 \cdot 67$ & 1.96 & $5 \cdot 76$ & 2.95 & 4.08 & 0.33 & 3.96 & $19 \cdot 36$ \\
\hline Normative Zn & 4.49 & 2.43 & 5.92 & 3.58 & $4 \cdot 16$ & 0.52 & 3.66 & $20 \cdot 5$ \\
\hline Vitamin $\mathrm{B}_{12}$ & $5 \cdot 76^{\star}$ & $-1 \cdot 28$ & $2 \cdot 20$ & -0.68 & $2 \cdot 89^{\star}$ & $-3 \cdot 48^{\star}$ & $7 \cdot 67^{\star}$ & 3.95 \\
\hline Folate & $4.65^{\star}$ & $4 \cdot 20$ & $7 \cdot 48^{*}$ & $7 \cdot 19^{*}$ & 3.08 & 2.48 & $3 \cdot 13^{*}$ & $25 \cdot 38^{*}$ \\
\hline Vitamin $B_{6}$ & 0.36 & 1.46 & $1 \cdot 80$ & $2 \cdot 28$ & 2.51 & 0.48 & 1.01 & 7.63 \\
\hline Riboflavin & 1.9 & $2 \cdot 37$ & $6 \cdot 34$ & 4.89 & $5 \cdot 57^{\star}$ & 2.56 & $2 \cdot 73$ & 23.98 \\
\hline
\end{tabular}

* The change is significant $(P<0.05)$.

†The estimated values of the level of improvement a child at the 90th percentile of nutrient intake would show in school test scores from term 1 to term 5 minus those of the level of improvement that the child at the 10th percentile (low intake) would show from term 1 to term 5 are reported. A positive outcome indicates that the high-intake child would improve more than the low-intake child; a negative outcome indicates that the lower-intake child would improve more than the high-intake child. 
group. The previously published results regarding cognitive performance in cohort I of the present study indicated a greater improvement in the RPM scores of the Meat group than in those of all the other groups ${ }^{(47,54)}$. In a combined analysis of cohorts I and II also, the Meat group showed greater improvements in the RPM scores than all the other groups ${ }^{(55)}$. The cognitive improvement in children of the Meat group may account for their improved school test scores.

Possible mechanisms for changes in test scores include higher cognitive scores, increased physical activity levels and exploratory and leadership behaviours, improvements in morbidity, and the presence of micronutrients that affect learning and brain function. The findings demonstrate that an increased intake of micronutrients such as folate, Fe, available $\mathrm{Fe}, \mathrm{Zn}$ and vitamin $\mathrm{B}_{12}$ and energy per kg body weight and riboflavin is directly related to the improvement in test scores and learning. The ingredients of the meat snack were rich in energy, $\mathrm{Zn}, \mathrm{Fe}$ and vitamin $\mathrm{B}_{12}$. The milk snack contained energy, $\mathrm{Ca}$, vitamin $\mathrm{B}_{12}$, vitamin $\mathrm{A}$ and riboflavin. $\mathrm{Fe}$, $\mathrm{Zn}$, folate, vitamin $\mathrm{B}_{12}$ and energy are important for cognition and learning ${ }^{(25,38,56-58)}$, and vitamin A affects child mortality and morbidity ${ }^{(59)}$, which in turn affect school attendance and readiness to learn.

Although milk has a lower content of Fe and Zn, which are extremely important for cognitive development, than meat, the Milk group showed impressive increases in test scores over time. Given the relative differential availability and cost of using various types of meat, fish, fowl and other small animals compared with those of milk, milk should certainly be utilised in school feeding programmes to improve academic performance where sources of a variety of meat are not available or affordable ${ }^{(60)}$. While previous studies have demonstrated that school feeding improves attendance ${ }^{(61,62)}$, only a non-significant increase in attendance was observed in the Meat and Milk groups in the present study.

The Plain Githeri and Control groups had lower scores in term 5 than at baseline in English, Kiswahili, Geography and Science and lower total test scores. Children in the Plain Githeri and Control groups may have scored lower than their own baseline scores because they did not progress as well as the other groups academically; thus, as the content of the examinations became harder, their scores were lower than those at baseline. It is important to note that the end-term tests administered in term 1 and in term 5 were not identical. The end-term test content, designed by the Kenyan Ministry of Education, had an increasing level of difficulty each term, meant to capture new topics taught in the curriculum. The results of cognitive testing for these two groups showed improvements in cognition, as indicated by the RPM test scores ${ }^{(47,54)}$.

Although children and their teachers and families were not blinded to their feeding group assignment, the hypotheses of the study were not shared with them at all. The only aspects that may have been known through popular knowledge were some of the health and academic benefits of milk, since milk has been used sporadically in ad hoc school feeding programmes in Kenya. We do not believe that improvements in tests scores are a result of the expectations of school officials and parents, and we do not think that children's ability to correctly answer questions regarding academic subjects was influenced by knowing that they were getting a meat, milk or plain githeri snack or no snack at all.

Another limitation of the present study is that it was not possible to carry out biochemical micronutrient analyses for the cohort II children due to funding limitations. However, biochemical analyses carried out on serum samples obtained from the cohort I children indicated a high prevalence of micronutrient deficiencies such as riboflavin, $\mathrm{Zn}, \mathrm{Fe}$, vitamin $\mathrm{A}$ and vitamin $\mathrm{B}_{12}$ deficiencies at baseline ${ }^{(63)}$. After the first year of the cohort I study, significant increases in plasma vitamin $\mathrm{B}_{12}$ concentrations were observed in children in the Meat and Milk groups compared with the Plain Githeri and Control groups $(P<0 \cdot 0005)^{(63)}$. For other micronutrients, no significant differences were found between the feeding groups or between each feeding group $v$. the Control group, but it is possible that infections and/or malaria could have obscured the effects ${ }^{(63)}$. As children in cohort II received the same feeding intervention and lived in the same area, it is likely that they experienced changes in micronutrient status similar to those experienced by cohort I. However, we were unable to correlate biochemical results with end-term test scores, since the term scores that we obtained were of the cohort II children and the biochemical data were of the cohort I children.

While the baseline data did not show significant differences in SES at baseline, our subjective observations of the school setting, classroom amenities and teacher absenteeism indicated that school quality, teaching and classroom physical amenities were not equal. Some of the best schools, based upon these observations, were the Plain Githeri schools. A possible reason for the Plain Githeri group not showing the same magnitude of improvement in test scores could be that it had the highest scores at baseline. On the other hand, the Meat group schools were of the poorest quality based upon the above-mentioned observations, yet ended up having higher tests scores in several academic subjects.

The incorporation of a wide variety of micronutrient-rich meat, or milk when meat is not available, by school feeding programmes can be a key component to promote academic success in children. Although there may be problems with long-term sustainability, parent, school and community participation in raising small animals and school gardens is a possible approach to school feeding. A wide variety of small animals, particularly goats, rabbits, poultry and fish, can be important sources of ASF for school feeding programmes. Nutrition education, both for parents and for schoolchildren, through schools and agricultural extension is also needed. The improvement of diet quality for schoolchildren can improve school performance and academic achievement. Improved educational attainment leads to improved learning capacity in children and qualifies them for further academic and vocational opportunities and can affect economic development. While school test scores are not particularly relevant to adult and elderly populations, improved physical activity, muscle strength, optimal mental functioning, protein quality, Fe deficiency, and vitamin $B_{12}$ deficiency-related anaemia 
are important issues in adult and elderly populations. ASF supplementation also has the potential to improve the nutritional status and function of adult and elderly populations, particularly muscle strength, cognitive function and overall quality of life.

\section{Acknowledgements}

The authors pay special tribute to the late psychologist and child development expert Dr Marian Sigman (UCLA) for her extensive input into the cognitive and educational aspects of the CNP. The authors thank Minnie Kamore, the field supervising psychologist, for obtaining the test scores from the schools and supervising the cognitive assessments and Montague W. Demment for providing the vision to support the funding of the study through the Global Livestock Collaborative Research Support Program (GL-CRSP).

The present study was supported by the GL-CRSP, United States Agency for International Development (DAN-1328-G00-0046-00), with partial funding from the James A. Coleman African Study Center (UCLA) and the National Cattleman's Beef Association (PCE-G-98-00 036-00). GL-CRSP, the James A. Coleman African Study Center and the National Cattleman's Beef Association had no role in the design and analysis of the study or in the writing of this article.

The authors' contributions were as follows: J. L. H. analysed data for her PhD dissertation and wrote the initial draft of the paper; R. E. W. designed and guided data analysis for the PhD dissertation and the present paper and edited the paper; N. O. B. oversaw the field research and served as the Kenyan Principal Investigator; O. M. G. guided the interpretation of the data; N. D. provided critical and relevant literature review and played a critical role in the drafting of the final paper and figures; C. G. N. designed, conducted and oversaw the research study, served as the Principal Investigator, wrote the paper, and had primary responsibility for the final content. All authors read and approved the final manuscript.

None of the authors has any conflicts of interest.

\section{References}

1. UNICEF (2006) State of the World's Children - Excluded and Invisible. New York, NY: UNICEF.

2. Caulfield LE, de Onis M, Blössner M, et al. (2004) Undernutrition as an underlying cause of child deaths associated with diarrhea, pneumonia, malaria, and measles. Am J Clin Nutr 80, 193-198.

3. Black RE, Allen LH, Bhutta ZA, et al. (2008) Maternal and child undernutrition: global and regional exposures and health consequences. Lancet 371, 243-260.

4. World Health Organization (2002) The World Health Report 2002 - Reducing Risks, Promoting Healthy Life. Geneva: WHO.

5. Black MM (2003) Micronutrient deficiencies and cognitive functioning. J Nutr 133, 3927S-3931S.

6. Eilander A, Muthayya S, van der Knaap H, et al. (2010) Undernutrition, fatty acid and micronutrient status in relation to cognitive performance in Indian school children: a crosssectional study. BrJ Nutr 103, 1056-1064.
7. Murphy S, Gewa C, Liang L, et al. (2003) School snacks containing animal source foods improve dietary quality for children in rural Kenya. J Nutr 133, 3950S-3956S.

8. Hambidge KM, Miller LV, Westcott JE, et al. (2008) Dietary reference intakes for zinc may require adjustment for phytate intake based upon model predictions. J Nutr 138, 2363-2366.

9. Gibson RS, Perlas L \& Hotz C (2006) Improving the bioavailability of nutrients in plant foods at the household level. Proc Nutr Soc 65, 160-168.

10. Brown KH, Wuehler SE \& Peerson JM (2001) The importance of zinc in human nutrition and estimation of the global prevalence of zinc deficiency. Food Nutr Bull 2, 113-125.

11. Hunt JR (2003) Bioavailability of iron, zinc, and other trace minerals from vegetarian diets. Am J Clin Nutr $\mathbf{7 8}$, 633S-639S.

12. Herbert V (1988) Vitamin B-12: plant sources, requirements, and assay. Am J Clin Nutr 48, 852-858.

13. Watanabe F (2007) Vitamin $B_{12}$ sources and bioavailability. Exp Biol Med (Maywood) 232, 1266-1274.

14. Guerrant RL, Oriá RB, Moore SR, et al. (2008) Malnutrition as an enteric infectious disease with long-term effects on child development. Nutr Rev 66, 487-505.

15. Stoltzfus RJ (2003) Iron deficiency: global prevalence and consequences. Food Nutr Bull 24, S99-S103.

16. Corapci F, Calatroni A, Kaciroti N, et al. (2010) Longitudinal evaluation of externalizing and internalizing behavior problems following iron deficiency in infancy. J Pediatr Psychol 35, 296-305.

17. Scrimshaw N (1998) Malnutrition, brain development, learning, and behavior. Nutr Res 18, 351-379.

18. Lozoff B, Jimenez E \& Wolf AW (1991) Long-term developmental outcome of infants with iron deficiency. $N$ Engl J Med 325, 687-694.

19. Zimmermann MB \& Hurrell RF (2007) Nutritional iron deficiency. Lancet 370, 511-520.

20. Stoltzfus RJ, Chwaya HM, Tielsch JM, et al. (1997) Epidemiology of iron deficiency anemia in Zanzibari school children: the importance of hookworms. Am J Clin Nutr 65, 153-159.

21. Walker P, O'Fallon A, Nelson K, et al. (2011) Vitamin $B_{12}$ deficiency in resettled Bhutanese refugees - United States, 2008-2011. MMWR Morb Mortal Wkly Rep 60, 343-346.

22. Healton EB, Savage DG, Brust JC, et al. (1991) Neurologic aspects of cobalamin deficiency. Medicine (Baltimore) $\mathbf{7 0}$ $229-245$.

23. Rasmussen S, Fernhoff P \& Scanlon K (2001) Vitamin $B_{12}$ deficiency in children and adolescents. J Pediatr 138, 10-17.

24. Graham SM, Arvela OM \& Wise GA (1992) Long-term neurologic consequences of nutritional vitamin $\mathrm{B}_{12}$ deficiency in infants. J Pediatr 121, 710-714.

25. Louwman MW, van Dusseldorp M, van de Vijver FJ, et al. (2000) Signs of impaired cognitive function in adolescents with marginal cobalamin status. Am J Clin Nutr 72, 762-769.

26. Black MM (2003) The evidence linking zinc deficiency with children's cognitive and motor functioning. J Nutr $\mathbf{1 3 3}$ 1473S-1476S.

27. Black MM (1998) Zinc deficiency and child development. Am J Clin Nutr 68, 464S-469S.

28. Bentley ME, Caulfield LE, Ram M, et al. (1997) Zinc supplementation affects the activity patterns of rural Guatemalan infants. J Nutr 127, 1333-1338.

29. Zimmermann MB, Jooste PL \& Pandav CS (2008) Iodinedeficiency disorders. Lancet 372, 1251-1262.

30. Mukudi E (2003) Nutrition status, education participation and school achievement among Kenyan middle-school children. Nutrition 19, 612-616. 
31. Alderman H, Behrman JR, Lavy V, et al. (2001) Child health and school enrollment: a longitudinal analysis. J Hum Resour 36, 185-205.

32. Pollitt E (editor) (1990) Malnutrition and Infection in the Classroom. Paris: UNESCO.

33. Fernando D, de Silva D, Carter R, et al. (2006) A randomized, double-blind, placebo-controlled, clinical trial of the impact of malaria prevention on the educational attainment of school children. Am J Trop Med Hyg 74, 386-393.

34. Hutchinson SE, Powell CA, Walker SP, et al. (1997) Nutrition, anaemia, geohelminth infection and school achievement in rural Jamaican primary school children. Eur J Clin Nutr 51, 729-735.

35. Kleinman RE, Hall S, Green H, et al. (2002) Diet, breakfast, and academic performance in children. Ann Nutr Metab 46, Suppl. 1, 24-30.

36. Florence MD, Asbridge M, Veugelers PJ (2008) Diet quality and academic performance. $J$ Sch Health 78, 209-215.

37. Berkman DS, Lescano AG, Gilman RH, et al. (2002) Effects of stunting, diarrhoeal disease, and parasitic infection during infancy on cognition in late childhood: a follow-up study. Lancet 359, 564-571.

38. Lukowski A, Koss M, Burden M, et al. (2010) Iron deficiency in infancy and neurocognitive functioning at 19 years: evidence of long-term deficits in executive function and recognition memory. Nutr Neurosci 13, 54-70.

39. Maluccio JA, Hoddinott J, Behrman JR, et al. (2006) The Impact of Nutrition During Early Childhood on Education Among Guatemalan Adults. Middlebury, VT: Middlebury College.

40. Crookston BT, Penny ME, Alder SC, et al. (2010) Children who recover from early stunting and children who are not stunted demonstrate similar levels of cognition. J Nutr 140, 1996-2001.

41. Neumann CG, Bwibo NO, Sigman M (1992) Diet Quantity and Quality. Final Report Phase II: Functional Implications of Malnutrition, Kenya Project. Los Angeles, CA: School of Public Health, University of California, Los Angeles.

42. Neumann C, McDonald M, Sigman M, et al. (1991) Relationships between morbidity and development in mildly to moderately malnourished Kenyan toddlers. Pediatrics $\mathbf{8 8}$, 934-942.

43. Neumann CG, Bwibo NO, Murphy SP, et al. (2003) Animal source foods improve dietary quality, micronutrient status, growth and cognitive function in Kenyan school children: background, study design and baseline findings. J Nutr 133, S3941-S3949.

44. Institute of Medicine (2006) Dietary Reference Intakes: The Essential Guide to Nutrient Requirements [J Otten, J Hellwig and L Meyers, editors]. Washington, DC: National Academies Press.

45. Murphy SP, Gewa C, Grillenberger M, et al. (2007) Designing snacks to address micronutrient deficiencies in rural Kenyan schoolchildren. J Nutr 137, 1093-1096.

46. Gewa C, Murphy SP, Bwibo NO, et al. (2005) Assessment of Snack Acceptance During a School Feeding Intervention in Rural Kenya: Research Brief 05-03-CNP. Davis, CA: Global Livestock Collaborative Research Support Program.
47. Whaley S, Sigman M, Neumann C, et al. (2003) The impact of dietary intervention on the cognitive development of Kenyan school children. J Nutr 133, 3965S-3971S.

48. Gewa CA, Murphy SP, Neumann CG (2009) A comparison of weighed and recalled intakes for school children and mothers in rural Kenya. Public Health Nutr 12, 1197-1204.

49. Grillenberger M, Neumann CG, Murphy SP, et al. (2003) Food supplements have a positive impact on weight gain and the addition of animal source foods increases lean body mass of Kenyan schoolchildren. J Nutr $\mathbf{1 3 3}$, 3957S-3964S

50. Weiss RE (2005) Modeling Longitudinal Data. New York, NY: Springer.

51. Gewa CA, Murphy SP, Weiss RE, et al. (2013) A school-based supplementary food programme in rural Kenya did not reduce children's intake at home. Public Health Nutr 16, $713-720$.

52. Neumann CG, Jiang L, Weiss RE, et al. (2013) Meat supplementation increases arm muscle area in Kenyan schoolchildren. Br J Nutr 109, 1230-1240.

53. Sigman M, Whaley SE, Neumann CG, et al. (2005) Diet quality affects the playground activities of Kenyan children. Food Nutr Bull 26, S202-S212.

54. Neumann CG, Murphy SP, Gewa C, et al. (2007) Meat supplementation improves growth, cognitive, and behavioral outcomes in Kenyan children. J Nutr 137, 1119-1123.

55. Neumann C, Murphy SP, Bwibo N, et al. (2005) Role of Animal Source Foods to Improve Diet Quality and Growth and Development in Kenyan School Children: Final Report of Cohort 2 Data Analyses. Los Angeles, CA: University of California, Los Angeles.

56. Sandstead HH, Penland JG, Alcock NW, et al. (1998) Effects of repletion with zinc and other micronutrients on neuropsychologic performance and growth of Chinese children. Am J Clin Nutr 68, 470S-475S.

57. Bryan J, Osendarp S, Hughes D, et al. (2004) Nutrients for cognitive development in school-aged children. Nutr Rev 62, 295-306.

58. Nguyen CT, Gracely EJ, Lee BK (2013) Serum folate but not vitamin B-12 concentrations are positively associated with cognitive test scores in children aged 6-16 years. $J$ Nutr 143, 500-504.

59. Imdad A, Herzer K, Mayo-Wilson E, et al. (2010) Vitamin A supplementation for preventing morbidity and mortality in children from 6 months to 5 years of age. Cochrane Database of Systematic Reviews (Online), issue 12, CD008524.

60. Djazayery A, Rahmani KH, Pourshariari M, et al. (2011) The effects of a daily milk supplement on the mental growth and school performance of female primary school children. Proc Nutr SOC 70, E230.

61. Taras H (2005) Nutrition and student performance at school. J Sch Health 75, 199-213.

62. Grantham-McGregor S (2005) Can the provision of breakfast benefit school performance? Food Nutr Bull 26, S144-S158.

63. Siekmann JH, Allen LH, Bwibo NO, et al. (2003) Kenyan school children have multiple micronutrient deficiencies, but increased plasma vitamin B-12 is the only detectable micronutrient response to meat or milk supplementation. J Nutr 133, 3972S-3980S. 